\title{
Muerte y resurrección de la Universidad de México
}

\begin{abstract}
A consumarse la independencia de México en el año de 1821, desaparecieron buena parte de las instituciones virreinales. Se acabó la Audiencia, se transformó el Cabildo, quedó sin efecto el patronato o patronazgo real sobre la Iglesia. Esta misma comenzó a sufrir los embates del Estado. México fué primero monarquía, después república federal, más tarde central, volvió a ser federación, fué imperio en una región, república en otra y, por fin, en 1867, república federal nuevamente. La Universidad sufrió todas las consecuencias de estas transformaciones. Su existencia o su desaparición fué cuestión de partido. El de la tradición, más tarde partido conservador, la defendió hasta donde pudo, el partido liberal se empeñó en destruirla para ser definitivamente extinguida de jure por un gobernante sostenido por el partido conservador, el emperador Maximiliano.
\end{abstract}

Las ideas que el partido liberal tenía sobre la Universidad las expresa el doctor don José María Luis Mora, en la exposición que se publica en sus Obras sueltas, tomo I, año de 1837. Dice el célebre precursor del movimiento reformista en México: "Desde los primeros dias de la independencia, se empezaron a advertir tendencias bien demarcadas, a la reforma de la educación científica y literaria: pero estas tendencias lejos de emanar de la generalidad, como sucedia en la educación primaria, no eran ni aun de la mayoría, que preocupada por el espiritu de rutina, tan propio de la pereza y desconfianza càracterística a los españoles, no conocía ni deseaba adelantos capaces de cambiar la marcha establecida. La minoría era la que deseaba y promovía débilmente estos cambios, de los cuales tam- 
poco se tenía por entonces una idea precisa en orden a su naturaleza y resultados. Los primeros ensayos que en esto se hicieron fueron parciales y de importancia muy secundaria. Una imperfectísima enseñanza de derecho público constitucional en los colegios y universidades; un curso de economía política hecho por el doctor Mora o sus discípulos en el colegio de San Ildefonso y la variación del traje talar de los estudiantes, promovida por él mismo, fué todo lo que se hizo bajo el gobierno del general Iturbide. El clero se declaró abierta y animosamenté contra estos cambios, y por aquí empezó su resistencia al conjunto de medidas y principios, emanados de ellos, que constituyen el programa del progreso: Iturbide supo, sin embargo, mantener lo que se habia hecho y en todo esto manifestó más cordura que sus sucesores que no acertaron a conservarlo. $\dot{A}$, la caída del imperio, el ministro universal don José Ignacio García Yllueca, comisionó al doctor Mora para que propusiere al gobierno in plan de reforma del colegio de San Ildefonso, que sirviese de modelo para el nuevo arreglo de todos los establecimientos de igual naturaleza existentes en la República. Mora había trabajado algo sobre la materia desde que recibió igual comisión de la Junta Provisional de gobierno en los primeros días de la independencia: y el plan que presentó, aunque menos malo que lo que existia, era todavía imperfectísimo."

Otra comisión, formada en el año de 1823, por los ministros don Lucas Alamán y don Pablo de la Llave, formuló un nuevo Plan General de Estudios, semejante al aprobado por las Cortes españolas. "En 1830 la decadencia de los colegios y de la Universidad," si gue diciendo el doctor Mora, era ya tan visible, que la administración retrógrada de aquella época, no pudo ya desentenderse de ella. El señor Alamán propuso e inició ante las Cámaras en su memoria de aquel año un plan de reformas mucho más irrealizable que el que había abortado la acalorada imaginación del señor De la Llave. El mérito principal de este trabajo consistía: en la división y clasificación de la enseñanza repartida en tantas escuelas, cuantos eran los ramos que debían constituirla: en el establecimiento de ramos antes desconocidos, y sin objeto en el sistema colonial, pero indispensables a un pueblo que debía ya gobernarse por sí mismo, y tener lo que se llama hombres de Estado; en la supresión de una multitud exorbitante de cátedras de teología, que se pasaban años 
enteros para que tuvieran un cursante, y eran de hecho en los más de los colegios absolutamente inútiles; $y$, por último; en la dedicación exclusiva de cada colegio a un solo ramo de enseñanza, o a los que con él tuvieron alguna relación. Los defectos del proyecto eran muchos y visibles: nada se hablaba en él de la suerte que debía correr la Universidad a la cual se le dejaba de hecho, sin destino; no se consolidaba un fondo para pagar la enseñanza, ni se le aumentaba el que existía insuficientísimo; finalmente, tampoco se trataba en él de facilitar a las masas los medios de aprender lo necesario para hacerlas morales y despertar en ellas los sentimientos de dignidad personal y de laboriosidad, que tan interesante es procurar a la última clase del pueblo mexicano."

Aparecen en la exposición del doctor. Mora las ideas cardinales del grupo progresista o liberal del que era conspicuo director: desprecio por la teología, deseo de predominio de la enseñanza a las masas populares, sobre la superior, que no fuera práctica y positiva, encaminada a dar al país los medios y preparar a los hombres para alcanzar el progreso que el partido consideraba como fin del gobierno. La Universidad representaba precisamente la imagen del retroceso. Por ello, cuando el doctor Mora participó activamente en el gobierno del vicepresidente don Valentín Gómez Farías en el año de 1833 y "los hombres positivos fueron llamados a ejecutar las reformas, especialmente de educación, se pusieron a contribución las luces de los tímidos que no saben más que desear y proponer; y se emplearon imparcialmente, formándolas de todos lados las capacidades que pudieron encontrarse", se constituyó una comisión de Plan de Estudios "que se ocupó ante todas las cosas, de examinar el estado de los establecimientos existentes destinados al objeto" $y$, como consecuencia de sus deliberaciones: "La Universidad se declaró inútil, irreformable y perniciosa: inútil por lo que en ella se enseñaba, nada se aprendia; porque los exámenes para grados menores eran pura forma, y los de los grados mayores muy costosos y difíciles, capaces de matar a un hombre y no de calificarlo; irreformable, porque toda reforma supone las bases del antiguo establecimiento, y sierido las de la Universidad inútiles e inconducentes a su objeto, era indispensable hacerlas desaparecer, sustituyéndoles otras supuesto lo cual no se trataba ya.de mantener sino el nombre de Universidad, lo que tampoco podía hacerse, porque representando esta pala- 
bra en su acepción recibida, el conjunto de estatutos de esta antigua institución, serviria de antecedente para reclamarlos en detalle y uno a uno como vigentes; la Universidad fué también considerada perniciosa porque daria, como da, lugar a la pérdida de tiempo y a la disipación de los estudiantes de los colegios que so pretexto de hacer sus cursos, se hallan la mayor parte del tiempo fuera de estos establecimientos únicos en que se enseña y se aprende; se concluyó pues que era necesario suprimir la Universidad. El Colegio de Santos, que por su institución debía ser una especie de foco en que deberian reunirse las capacidades científicas y literarias, para después tomarlas de alli y emplearlas en el servicio público, no podía ya desempeñar ese loable objeto, por la sencillísima razón de que las capacidades del país no podian caber, ni tampoco querian ya reunirse en él."

Este dictamen apasionado y de evidente carácter político, dió lugar al decreto de 19 de octubre de 1833 que dice: "Se autoriza al gobierno para arreglar la enseñanza pública en todos sus ramos en el Distrito y territorios. Se formará a este efecto un fondo de todos los que tienen los establecimientos de enseñanza actualmente existentes, pudiendo además invertir en este objeto las cantidades necesarias."

Con este decreto se inicia la tragedia que ha de padecer la Universidad en el siglo diecinueve y que se manifiesta en los siguientes

Acto primero:-Decreto del vicepresidente de la República, don Valentín Gómez Farías del mismo diecinueve de octubre de 1833, que dispone:

10. La supresión de la Universidad de México y el establecimiento de una Dirección General de Educación Pública para el Distrito y territorios de la Federación;

$2^{\circ}$ La Dirección tendrá a su cargo todos los establecimientos públicos de enseñanza, los depósitos de los monumentos de artes, antigüedades e historia natural, los fondos públicos consignados a la enseñanza, y todo lo perteneciente a la instrucción pagado por el gobierno y nombrará por primera vez a los profesores de los establecimientos, de una terna propuesta por los directores. Después se establece la oposición como medio de selección al personal docente. 
El decreto establece reglas para la administración de los fondos con que dote el gobierno a la flamante institución.

Ni tardo ni perezoso el gobierno, un día después de expedido el decreto anterior, se nombra a don Manuel Eduardo de Gorostiza para que "pasando a ese edificio (de la Universidad) asociado de un escribano, manifieste esta providencia y la de la supresión de la misma Universidad, al Rector de Escuelas y reciba de él la casa, muebles, biblioteca, capilla con sus paramentos y vasos sagrados, archivo, libros, cuentas, escritura y todo lo demás que pertenezca o pueda pertenecer a la Universidad, bajo formal inventario." Deberá arreglarse, el ilustre dramaturgo a las instrucciones que se le dieron para recibir el Colegio de Santos, el 23 de octubre de 1833. Además, ese día, el Vicepresidente expide una ley "en la que crea seis planteles de educación superior llamados establecimientos. Uno era el de estudios preparatorios, y los cinco restantes se llamaron de estudios ideológicos y humanidades, de ciencias físicas y matemáticas, de ciencias médicas, de jurisprudencia y de ciencias eclesiásticas. "Habrá, además, un establecimiento con cátedras de botánica, de agricultura práctica y de química aplicada. Todo dependia de la Dirección General de Instrucción Pública, formada por los directores de los planteles." ${ }^{1} \mathrm{El}$ mismo día 23, un nuevo decreto creaba el "Primer establecimiento de estudios Preparatorios. Se darían en él las siguientes cátedras: 'Primera y segunda de latinidad, lengua mexicana, otomi, francés, inglés, alemán, griego, principios de lógica, aritmética, álgebra y geometría, teologia natural, neumatología y fundamentos filosóficos de la religión'. Las cátedras se darán en el antiguo Hospital de Jesús, desde el once de mayo hasta el treinta y uno de marzo, se descontará a los profesores el sueldo del día que falten a clase y se les asigna un sueldo anual que no bajará de 1,200 pesos, ni excederá de 1,500. Establece el decreto el orden serial de las materias y los requisitos para que el estudiante sea admitido al estudio de la medicina, de la jurisprudencia y de las ciencias eclesiásticas. Establece después los grados académicos de doctor que deberán conferirse en las facultades mayores, mediante los requisitos que el decreto establece". El artículo 20 es particularmente significativo: "El Seminario Conciliar queda bajo la inspección de la Dirección General, para cuidar que precisamente se guarde y observe en él la planta que dió a los de su clase el Conci- 
lio de Trento en el capítulo 18 de Reformatione, sección 23, en la totalidad de la enseñanza que prescribe y demás disposiciones que contiene, tomando conocimiento de los reglamentos que se hayan hecho o hagan para su debido cumplimiento."

Se prescribe, además, que en las enseñanzas que se impartan en el seminario, se sujetarán a las reglas a que quede sometida la enseñanza libre. Se prohibe a los alumnos el uso de trajes peculiares o distintivos.

En sus disposiciones generales, el decreto establece la enseñanza libre, que es la que no se imparte en los establecimientos públicos; pero esta enseñanza se sujetará en cuanto a doctrinas, "puntos de policía y en el orden moral de la educación a los reglamentos generales que se dieren sobre la materia." Prescribe que un catedrático puede desempeñar hasta dos cátedras en los colegios y que "cuando no hubiere profesores en la República para algunos ramos de enseñanza, podrán contratarse extranjeros, y asignarles hasta 3,000 pesọs de sueldo y costearles su venida." Por último "quedan sometidas las bibliotecas públicas y nacionales y los teatros, a la Dirección General de estudios, creada por la Ley de 19 de octubre de 1833".

Segundo acto.-La supresión de la Universidad no era sino un capitulo de las teformas que el partido liberal, o como se llamaba entonces progresista, pretendia implantar en el país. Se pretendia ya resolver el problema cconómico del Estado. "Las notabilidades pertenecientes al directorio progresista -dice don Carlos Pereyra- 2 se reunieron el 14 de noviembre de 1833, en la Dirección de Instrucción Pública, bajo la presidencia de don Valentin Gómez Farías y declararon que el déficit permanente de las rentas públicas, no podía cubrir con nuevos impuestos, ya que no habia industria y que el comercio estaba desnivelado y amenazado de muerte por el contrabando, de que tomaría mayor extensión al acentuarse los gravámenes sobre el tráfico lícito. Era imprescindible apelar a recursos extraordinarios." Uno de ellos fué la ocupación de los bienes del clero. Esta medida de carácter radical produjo la consiguiente reacción entre los adversarios políticos de los liberales, esto es, los de los conservadores. Vino el pronunciamiento, secretamente favorecido por el propio presidente de la República, don Antonio López de Santa Anna. Se dió pues, el caso curioso de que el Presidente se pronunciara contra el Vicepresidente, y don Valentín Gómez Fa- 
rías fúé derribado. Se inicia la segunda etapa de la tragedia de la Universidad: El Supremo Gobierno dispuso el 31 de julio de 1834 el restablecimiento de la Universidad. Se declara, en el documento en que se da a conocer este acuerdo que "La Dirección General que se estableció por una ley, y de la cual debía ser presidente el Vicepresidente de la República, se opone notoriamente a la Constitución que en muchos de sus artículos designa las atribuciones de aquél y establece cierta independencia de este magistrado del supremo gobierno general, independencia que no puede subsistir hallándose de presidente de la dirección que está sujeta a la Secretaría de Relaciones, $\mathrm{y}$ que a pesar del objeto noble de su instituto, parece incompatible con el alto carácter y atribuciones del segundo magistrado de la República." Se aducen otras razones: "que imponen al gobierno la más estrecha obligación de volver las cosas al estado que tenían, por el corto espacio de treinta días y entre tanto se organiza el plan general de estudios." Estas razones son: el haber tomado para fondo de los nuevos establecimientos los de la Universidad "contrariando fundaciones expresas y terminantes y atacando la propiedad de los doctores." Haber hecho lo mismo con fondos del Seminario de Minería, "destinados exclusivamente para cierta clase de jóvenes que tienen derecho a reclamar el cumplimiento de las fundaciones que se hicieron en su favor; que se ha privado al erario de ingresos que no han sido sustituídos por otros, y que, por último "el arreglo de los nuevos establecimientos se formó sobre bases opuestas a la justicia y a la conveniencia pública."

Los resultados más importantes de esta disposición son los siguientes: Se suspenden los establecimientos creados por el decreto de 1833, volviéndose al estado en que se hallaban entonces los colegios de San Ildefonso, San Juan de Letrán, San Gregorio y Seminario de Minería, devolviéndoles los fondos y bienes que tenían; los doctores de la Universidad "se reunirían inmediatamente en claustro pleno para acordar la alteración que deba haber en el plan de estudios que se organice con respecto a la Universidad, y que debeIá plantearse bajo las siguientes prevenciones: Primero, que en la Universidad se enseñen aquellos ramos que no se estudien en los colegios; segunda, que se hagan compatibles las distribuciones de la Universidad con las de los colegios; tercera, que propongan inmediatamente al gobierno la variación que juzguen conveniente en 
todo el sistema de estudios." El claustro de Medicina procedería a hacer una visita al establecimiento de ciencias médicas, "que por ahora se mantendrá en la parte instructiva hasta que con vista del informe de la visita, el gobierno disponga de lo conveniente, asi sobre el método de enseñanza como sobre autores y cátedras $\mathrm{y}$, por último, el gobierno nombraría una junta que asociada con los rectores de los colegios, proponga el plan de estudios de que se habla en este decreto y en el que se concilien "las mejoras que exige el estado de civilización y los fondos con que esta pueda promoverse."

Un plan de estudios provisional fué expedido el 12 de noviembre de 1834. En él se establece que en el colegio de San Juan de Letrán se enseñarán las primeras letras, el dibujo, la gramática castellana, latina y francesa, la retórica y los derechos natural, canónico $\mathrm{y}$ civil; en el de San Ildefonso, las mismas materias, con excepción del dibujo y la gramática francesa; en el de San Gregorio las mismas que en el de San Juan y, además, la música vocal e instrumental y la teología moral. En el de Minería, las gramáticas castellana, francesa e inglesa, las matemáticas, la física, la química, la mineralogía, la cosmografía y el dibujo.

En dicho plan se establece minuciosamente el régimen de las cátedras, el número de profesores que deberán impartirlas y las obligaciones de los catedráticos. Restablece el uso del traje talar para los estudiantes y determina que todos los catedráticos presentarán al fin del año una memoria comprensiva de los adelantos que haya hecho la ciencia que enseñan en el año que ha transcurrido, a fin de que, con el informe del respectivo claustro, por conducto del gobierno pasen estas memorias a las Cámaras para las reformas que en el plan de estudios quieran hacer. Se crean actos llamados academias o sabatinas para que discutan puntos relacionados con sus cstudios, los maestros y alumnos de los colegios. Se recomienda, también, que en las academias que se organicen se ejercite la elocuencia en los estudiantes y se estudie literatura. La primera para acostumbrar a los jóvenes en el ejercicio del foro o del púlpito, "según la profesión que eligieren y se pide la lectura de autores clásicos", procurando "que el genio pueda desplegar con libertad en estos actos académicos."

Los estudios médicos se organizan en el convento de Belén, que toma el nombre de colegio de Medicina, y se establecen las cá- 
tedras de anatomía y medicina operatoria, fisiología e higiene, patología externa, patología interna, clínica interna, terapéutica y materia médica, elementos de botánica y de farmacia, obstetricia y enfermedades de mujeres y niños. Los estudiantes para matricularse presentarán el título de bachilleres en filosofía y certificación de un curso de química.

Todo el título II se dedica a la organización del colegio de Medicina. Las principales disposiciones de él son las siguientes: Tres años para gue los estudiantes puedan obtener el grado de bachiller, dos más dedicadós a las prácticas y a las clínicas. "Los que aspiren al grado de licenciado o de doctor, harán la función correspondiente si no son incorporados con arreglo a las constituciones de la Universidad. Las cátedras se impartirán diariamente. El sueldo de los profesores será de 1,200 pesos anuales. Se obtendrán las cátedras por oposición y los catedráticos serán inamovibles, salvo casos graves, calificados por las dos terceras partes de los profesores reunidos en junta general y con aprobación del gobierno. Se formará un cuerpo de agregados que sustituirán a los profesores cuando éstos se hallaren temporalmente impedidos. El cuerpo de agregados se constituirá por oposición de los candidatos. Concurrirán a los exámenes y serán preferidos en las vacantes. Para desempeñar una cátedra, deberá el candidato haber obtenido el grado de doctor."

El título In de este plan habla del gobierno de la Universidad que residirá en el rector, el maestrescuela y los claustros mayor y menor y de hacienda. El claustro mayor estará formado por todos los doctores residentes en la ciudad de México y para "formarlo bastarán doce". El menor "es una sección del mayor, y se compondrá de dos doctores por cada facultad, nombrados por el claustro mayor inmediatamente después de la elección del rector." Se conserva para estos doctores el nombre de consiliarios. El Claustro de hacienda lo forman la mitad de los catedráticos por turno, que durará lo que el rectorado. El Rector lo nombrará el claustro mayor previa postulación de candidatos del menor. La elección "se reglamentará por un estatuto particular, $y$ puede recaer en los doctores médicos y en los filósofos (cuya denominación de maestros queda extinguida), y en los casados." El rector se nombrará cada tres años, el día 10 de noviembre. El maestrescuela sería designado conforme a los cánones y concordatos de las Nación y el nombramiento de Vice- 
cancelario en el caso de que vacare la dignidad de Maestrescuela. "Este nombramiento no se limitará a los doctores más antiguos, sino que podrá recaer en los que han sido rectores y en los catedráticos y jubilados."

"Solamente la Universidad podrá conferir los grados académicos de doctor, licenciado y bachiller." El primero se otorgará a los licenciados que quieran obtenerlo previo el examen correspondiente y a todos los sabios que incorporare la Universidad. Unos y otros tendrán los mismos derechos. La incorporación se hará por acuerdo del Claustro mayor. El grado de licenciado se conferirá a los que hayan concluído los estudios de los colegios y los de la Universidad, y sustentado el examen correspondiente; el de bachiller se otorgará a los que hayan terminado los estudios en los colegios. Los miembros del clero regular, que tengan facultad para ello por sus constituciones y los estudiantes de los Estados podrán recibir los grados de la Universidad con los requisitos que establezca un estatuto particular.

Se reglamentan inmediatamente después los estudios que deberán hacerse en la Universidad, estableciendo que, en esta última se completan y perfeccionan los hechos en los colegios. Las cátedras existentes hasta el momento de la redacción del plan quedan refundidas en las siguientes: En teología, la que se llamaba de Prima de teología, "será de lugares teológicos; la de Escritura conservará su nombre y la de Vísperas será de Historia Eclesiástica." En cánones "subsistirá la cátedra de Vísperas, en que se enseñará la teoría de los cánones acomodada a las iglesias de América y en lugar de la de Disciplina y Prima, se establecen dos cátedras de Fuentes de la disciplina eclesiástica." En Leyes, la cátedra de Prima será primera y segunda de derecho patrio y la de Vísperas será de derecho público. En filosofía, en lugar de la cátedra de Prima se establece una de Zoología. En medicina, las cátedras de Prima, Vísperas y Matemáticas, serán de Medicina legal, la primera, de Medicina hipocrática la segunda y la tercera de Historia de la medicina."

Los exámenes se realizarán: para que los candidatos opten a los grados de bachiller, licenciado, doctor: para obtener una cátedra y para pasar de un curso a otro. Todos ellos, excepto el de doctor deberán concluir con la aprobación o reprobación de los exami- 
nados. "En todos los exámenes se señalará una propina moderada a los examinadores y a todos los que deban asistir a ellos."

Entre las disposiciones generales de este plan se destacan estas dos que tienen singular importancia: La del artículo 101 que dice: "El gobierno recomienda a la Academia de Jurisprudencia, al Nacional Colegio de Abogados y a la excelentísima Suprema Corte de Justicia, el mayor empeño y escrupulosidad en los exámenes de los letrados, supuesto que la mayor parte de los vicios que se atribuyen a la administración de justicia, quizás lo son de los que sin tino, sin cordura y sin acierto patrocinan en los tribunales los negocios civiles y criminales, contraviniendo a las Leyes." $\mathrm{Y}$ la contenida en el artículo 103 del Plan: "La Nacional y Pontificia Universidad, el Nacional Colegio de Abogados y la Academia de Jurisprudencia, servirán al gobierno, cuando lo estiman conveniente, de cuerpos consultivos, y bajo la responsabilidad de las propias corporaciones darán su dictamen sobre los puntos que se pasaren por el Ministerio de Relaciones a su examen."

Por último hay otras dos que merecen citarse: "Todas las corporaciones a quienes comprende este plan, procurarán en sus ramos respectivos dar anualmente una noticia de las obras que salieren a luz, el juicio o censura de sus doctrinas y las ventajas que puede traer su lectura a los estudiantes de aquel ramo" y otra: "Para las calificaciones literarias, su examen, incorporación, etc., sólo se atenderá a la aptitud y al saber, sea cual fuere el origen y nacimiento; mas cuando se tratare de algún destino o' empleo, se tendrán asimismo presentes las leyes vigentes; y si tuviere el agraciado que ponerse al frente de la educación de la juventud, deberá requerirse a más buena conducta y moralidad."

Este plan fué complementado con un "Reglamento" que el claustro de Consiliarios de la Nacional y Pontificia Universidad formuló para la elección del Rector de las escuelas y otro para cátedras y cursos en la Universidad, que contiene los libros de textos que en ellas deben estudiarse. Este último fué aprobado el 16 de febrero de 1835. En la comunicación dirigida al Rector enviándole el Reglamento se dice que los maestros tenían obligación de acomodar las doctrinas "a nuestra posición y costumbres y deberían ilus- 
trar" sus máximas "con autores clásicos antiguos y modernos, omitiéndose aquellos puntos que no están en consonancia con la religión, usos y política de nuestro país."

\section{NUEVOS PLANES DE REFORMA}

De la Nacional y Pontificia Universidad de México no quedaron más huellas que un escudo con la imagen de Minerva, y el dibujo, en la égida, de las armas pontificias y algunas alusiones en las obras literarias de la época, las de Payno, entre otras. Mientras, el gobierno legislaba activamente sobre la educación pública en el país. Así, por ejemplo, el 19 de diciembre de 1842 se expide un decreto sobre el arreglo de la educación primaria, que la establece obligatoria y gratuita. Se enseñará a los niños a leer, escribir y las cuatro operaciones aritméticas y la doctrina cristiana. Se establecerá una escuela de niños y niñas por cada diez mil habitantes. Se fundará una escuela normal. Se publicarán cartillas y libros de texto elementales. Se abrirán escuelas para adultos. Será obligatorio el concurrir a la escuela a los niños de siete a quince años de edad y serán penados los padres o tutores que no envíen a sus hijos o pupilos a los colegios primarios. Los conventos pueden organizar escuelas de este tipo, pero los profesores deberían ser aprobados por la Dirección General de Instrucción Primaria que será el organismo que vigile toda la enseñanza de este tipo, que además se establece de acuerdo con el sistema lancasteriano.

El siete de diciembre del mismo año aparece el reglamento del decreto anterior. Se fijan en él las materias que deberán enseñarse en la Escuela Normal. Se advierte que habrá libertad de enseñanza; pero los maestros no atacarán a la religión, ni se permitirá que propalen ideas contrarias a las buenas costumbres, a las instituciones políticas y a las leyes vigentes en el país.

Es importante el Decreto de 18 de agosto de 1843 expedido por don Antonio López de Santa Anna, como Presidente Provisional de la República "con el fin de dar impulso a la Instrucción Pública, de uniformarla y de que se haga cierta y efectiva su mejora presente, como progresivos y firmes sus adelantos futuros." $\mathrm{El} \mathrm{de-}$ 
creto va refrendado por el Ministro de Justicia e Instrucción Pública don Manuel Baranda. El decreto establece estudios preparatorios uniformes para las cuatro carreras que admite el ordenamiento, a saber: la del foro, la eclesiástica, la de medicina y la de ciencias naturales. Esta última comprendía las de ciencias matemáticas, físicas, químicas y biológicas. La enseñanza preparatoria comprendía el aprendizaje de los idiomas, de la ideologia: la lógica, la metafísica y la moral; las matemáticas y la física elementales; la cosmografía y la geografía; la economía política; el dibujo y la cronología, que así se llamaba entonces a la historia. Los estudios se harian en los colegios de San Ildefonso, San Gregorio, San Juan de Letrán, Medicina y Mineria.

Los estudiantes de los colegios no tenían necesidad de concutrir a la Universidad. Los profesores de ésta que no tuvieran grupo por las modificaciones que el decreto introducía al sistema de enseñanza superior en la República, tendrían la obligación "de trabajar obras elemertales para las materias que correspondan a sus cátedras. Sin perjuicio de este trabajo darán, anualmente, una memoria relativa a las propias materias y un análisis de las obras que hayan publicado y que crean puedan servir para la enseñanza elemental y clásica." (Art. 84 del Decreto). Se confiere a la Universidad el derecho de expedir títulos de bachiller a los examinados en los colegios $y$ otorgar los grados de licenciado y doctor mediante el examen cor respondiente. En la Junta General Directiva de la Instrucción Pública, la Universidad estaría representada por el rector.

En la carrera del foro se cursarían las siguientes materias: derecho natural y de gentes, derecho público y principios de legislación, elementos de derecho romano, derecho civil y criminal, derecho canónico, práctica profesional. En la carrera eclesiástica: historia eclesiástica y lugares teológicos, sagrada escritura, teología, estudio de los padres y disciplina eclesiástica y se terminaría con la práctica correspondiente. En la de medicina: anatomía descriptiva y elementos de anatomía general, fisiología y elementos de higiene, farmacia teórica y práctica, patología general y externa e interna, clínica quirúrgica y médica, medicina operatoria, terapéutica médica y materia médica, obstetricia y medicina legal. La carrera de ciencias naturales comprendía el estudio de las matemáticas, la física, la astronomía, la cosmografía, la química, la geologia, la geodesia y la orictogno- 
cia, la mineralogia, la botánica y la zoología. Las carreras del foro y la eclesiástica tendrían una duración en sus estudios de seis años. La organización de los estudios de ciencias naturales debería hacerse por un decreto especial "que propondrá al gobierno el director del Colegio de Minería." En esa organización se tendría "por objeto ampliar el estudio de ciencias naturales a la mayor extensión posible; ponerlo al nivel del estado que tienen hoy en Europa y preparar sus adelantos según los progresos que tuviesen los conocimientos que comprenden." (Art. 10 del Decreto).

Para sostener las enseñanzas preparatorias y profesionales se establecian estos arbitrios: "10 Los productos de los bienes que cada uno de los colegiados poseía; $2^{\circ}$ las asignaciones que les concedía el tesoro público, y $3^{\circ}$ el seis por ciento del importe líquido de las herencias "que hubiere desde la publicación de esta ley, ya sean extestamento $\circ a b$ intestato y que no sean directas forzosas... La misma pensión y en su misma cuota proporcional a st1 importe, pagarán cada uno de los legados y mandas, sean de la clase que fueren. Las herencias vacantes serán también a favor del fondo de instrucción pública." (Artículos 65 y 66). La Junta Directiva General de Estudios en la capital de la República estaría integrada "por el rector de la Universidad de México y rectores de los colegios de San Ildefonso, Letrán y San Gregorio, del director del Colegio de Medicina, del director del Colegio de Minería, del presidente de la Compañia Lancasteriana y de tres individuos de cada carrera nombrados por el gobierno. Era presidente nato de la Junta el Ministro de Instrucción Pública y Vicepresidente el Rector de la Universidad de México. (Art. 78.) Por último se agregaban al colegio de Minería el Museo Nacional y el gabinete de historia natural que ya existían.

El cuadro de la instrucción pública en México se iba completando con la creación de nuevas instituciones. En el año de 1853 se fundaron las escuelas de Agricultura y de Artes y Oficios. Diez años después la Escuela Práctica de Minas y la de Veterinaria. Esta última y la de Agricultura formaron el Colegio Nacional de Agricultura. Su plan de estudios comprendia la enseñanza primaria, la secundaria y la superior. En el mismo año se reinstaló la Compañía de Jesús y se le dieron facultades para abrir colegios; y en 1854 se fundó la Escuela de Comercio. 
A fines del año de 1854 se intenta una nueva reforma al sistema de enseñanza en México. Redacta el plan don Teodosio Lares y lo apoya el presidente Santa Anna. Las características de ese ordenamiento son las que en seguida se expresan:

Seguiría impartiéndose la enseñanza religiosa en la escuela primaria. La preparatoria o secundaria constaría de seis años, dividida en dos períodos de tres cada uno. En el primero llamado de humanidades, se estudiaría gramática latina y castellana; historia sagrada y profana, universal y de México y literatura. El segundo período se consagraba a los estudios elementales de filosofía. El plan comprendía psicología, lógica y metafísica, religión y filosofía moral, elementos de matemáticas, física experimental, nociones de química, cosmografía y geografía, francés e inglés. Se expedirían una seric de reglamentos complementarios y en ellos se determinaria la distribución gradual y progresiva de las materias religiosas; "el curso de filosofía ( $2^{\circ}$ año del $2^{\circ}$ período) debe comprender el plan todo de la religión y del enlace que tienen entre sí sus verdades y dogmas. La secundaria tendrá academias religiosas para la ampliación de estos estudios." 3

La enseñanza superior se impartiría en las facultades de Filosofía, Medicina, Jurisprudencia y Teología en tres períodos, que capacitarían al estudiante para obtener los grados de bachiller, licenciado y doctor. La de Filosofía comprenderia los estudios de lenguas y literaturas griega y latina y literatura general; historia general y particular de México; historia de la filosofía y un curso comparativo de la filosofía antigua y moderna. Así quedaba integrada la sección de Filosofía de la Facultad. Los estudios en esta sección se harian en dos años para la licenciatura y uno para el doctorado. La facultad comprendía otras dos secciones: la de ciencias físicomatemáticas y la de ciencias naturales. Ambas comprendían seis años de estudio, dos para cada uno de los grados. En la primera se estudiaban matemáticas puras, mecánica, topografía, geodesia, física experimental, geografía y astronomía. La segunda abarcaba las siguientes materias: matemáticas, química, botánica, zoología, mineralogía, geología y paleontología.

Para ingresar a las facultades de Jurisprudencia y Teología se había menester del bachillerato en filosofía. En la de Jurisprudencia, como novedad se implantaba un curso de filosofía del derecho 
en el doctorado. El resto de las materias eran las tradicionales en esta escuela. En la Facultad de Teología se establecían un curso de historia eclesiástica y disciplina de la Iglesia mexicana y otro de historia de las ciencias eclesiásticas, además de los habituales y en Medicina uno de historia de las ciencias médicas.

El plan establecía un ramo llamado de Estudios Especiales "que comprendía profesiones y carreras no sujetas a la recepción de grados académicos, como agricultura, comercio y artes." "4

Declaró la ley como establecimientos oficiales a las Universidades, institutos, colegios y escuelas especiales. En las Universidades se harian los estudios para alcanzar los grados de licenciado y doctor. Se reconocian oficialmente las Universidades de Guadalajara y de Yucatán. A la de México con su autoridad nacional y pontificia se le reconocía el carácter de central. El bachillerato se otorgaba a los estudiantes salidos de los colegios previo el examen presentado en la Universidad. Se restablecieron las formalidades y pompas inherentes de las funciones y actos universitarios consagrados por la tradición. Las escuelas de Minería, Comercio y Agricultura quedaren incorporádas al Ministerio de Fomento y la Academia de Bellas Artes al de Relaciones Exteriores.

Los Seminarios se incorporaban, a su vez, a las Universidades de la diócesis en que estaban instalados y en caso de no haberla, a la de México. Competía al Ejecutivo la dirección de la enseñanza primaria: pero la técnica y administrativa de la secundaria y superior a la Universidad, "quien la ejercía por medio de un Consejo y de un inspector general de la Instrucción Pública". Por último esta ley, expedida el 19 de diciembre de 1854 ordenaba que la Universidad debería reorganizar sus estudios de acuerdo con los preceptos en ella contenidos y quedar instalada, bajo la presidencia del Consejo de Instrucción el primero de mayo de 1855.

\section{DRAMATICA LUCHA POR LA PERVIVENCIA DE LA UNIVERSIDAD}

En realidad el plan "Lares" no pudo llevarse a cabo. El triunfo de la revolución de Ayutla, dando al traste con la administración, Santa Anna restableciendo el federalismo, trajo consigo el dominio, 
en el gobierno del partido liberal, enemigo jurado de la Universidad. El presidente Comonfort designa en comisión a los ciudadanos José María Benítez, José María Cortés y Esparza, Blas Balcárcel y Manuel Berzanzo para que estudien las condiciones de la Universidad y propongan remedio para sus males. La comisión visitadora, recurre a los archivos de la Universidad, lee cuidadosamente la crónica, entonces manuscrita del bachiller Cristóbal de la Plaza, se informa de las Constituciones que han regido a la institución por varios siglos, se interesa por los cedularios y otros documentos de su archivo y en 10 de septiembre de 1856 rinde al Ministro de Justicia un largo y bien meditado informe sobre el estado de la institución.

Comienzan los comisionados por hacer una reseña histórica de la Universidad. Hacen la crítica de todas las medidas que se han ideado para su reforma, a partir de la independencia. Afirma que la Universidad se encuentra en un estado más informe, sin duda que el día de su erección y aguarda del legislador le dé nuevo ser y nueva vida para proseguir la carrera que con tanta gloria había comenzado. Los estatutos que la han regido han caido unos en desuso, otros han sido inadaptables a los sistemas de gobierno y otros han quedado atrás en el progreso de los conocimientos humanos. De ahí las múltiples disposiciones que los han modificado, derogado, aclarado, "hasta que el trastorno general que ha conmovido nuestra sociedad y en la rápida sucesión de hombres y partidos que han obtenido el poder en nuestro infortunado país, la Universidad tan brillante, tan honrada en los tiempos pasados, por el lustre que le han dado sus hijos y por estar en consonancia con el sistema político, moral y religioso de su época, hoy es un edificio arruinado en su parte inmaterial y casi en completo aniquilamiento." "

Enumera la comisión los estatutos caídos en desuso, a saber, entre otros, los que daban jurisdicción penal al rector; los que establecían los privilegios disputados por el Colegio de Santos, los que establecían la concesión de grados por suficiencia.

Describe el documento después el estado en que se encuentra la Universidad a mediados del siglo pasado. En los bajos se encuentra la capilla, el salón llamado General, en el que se realizan los actos académicos, la vivienda del bedel, las oficinas de la Secretaría $y$ un lugar, cerrado por una verja donde se guardan las antigüedades del museo. En el piso superior la biblioteca, la sala de claustros, el 
Museo Nacional y las aulas, en que se imparten las distintas cátedras. Hacia el exterior, en los bajos, tiendas y habitaciones particulares.

Enumera el informe las funciones religiosas que se realizan en la Universidad. En el aula mayor se pueden contemplar los hombres ilustres que la han honrado por sus letras y los puestos que han ocupado en la Iglesia y el Estado. En esta aula se otorgan los grados y se realizan los actos solemnes de la Universidad y los Colegios. También la presta la Universidad al Estado para la celebración de elecciones populares o para conmemoraciones cívicas, para sesiones de la junta patriótica y de corporaciones establecidas para distintos objetos.

La biblioteca erigida en el año de 1760 por el doctor Beye de Cisneros, se sostiene con el producto de las tiendas que renta la Universidad en los bajos de su edificio. El producto de ellas debería dividirse en cuatro partes: dos destinadas a los sueldos de otros tantos doctores, bibliotecarios, una para reparaciones y aseo y la última para la compra de libros. Sin embargo, dicen los comisionados, "abusivamente se ha estado disponiendo para pago de sueldos de catedráticos en estos últimos años de la parte destinada a compra de libros; siendo así que prohibe real cédula distraer de su objeto tales rentas. A esta biblioteca se pasaron de orden del virrey don fray Antonio María de Bucareli y Ursúa varios y exquisitos documentos de antigüedades mexicanas, y en esa época existían 3,410 volúmenes con varios instrumentos matemáticos y quirúrgicos. Hoy, el inventario formado en noviembre de 1842 , asciende el número de volúmenes a 9,131. De las antigüedades que existían en la biblioteca, la mayor parte se pasaron al Museo donde deben conservarse. Si la parte de fondos destinada a compra de libros no se hubiera distraido de su objeto, la biblioteca de la Universidad sería la mejor de las destinadas al público, pues se hallaría enriquecida con multitud de obras que dieran instrucción, tanto a los cursantes como a los profesores que no tienen facultades sobrantes para la compra de todos los autores de una ciencia."

La renta anual que percibía en esa época la Universidad era de 6,368 pesos, 4 reales, 5 granos. La comisión reconoce la probidad del Síndico tesorero que administraba estas rentas, don José María Durán; pero nota falta de método en las cuentas y objeta el pago 
que se hace a los doctores por asistencia a las funciones de la Universidad, de cantidades que van de tres pesos, si el que la percibe asiste a la función completa y un peso y cuatro reales si sólo concurre a una parte de ella. Estima la comisión que estas cantidades, sobre ser indecorosas, no hay autorización legal para cubrirlas y por lo tanto juzga que "el gasto es abusivo".

Pasa a discutir la comisión las ventajas de la enseñanza libre, decretada en Francia por la Asamblea Legislativa en 1848 y propone "que si se adopta en nuestra patria el principio de la enseñanza libre, sea en toda su latitud ilimitada, sin trabas ni restricciones. Subsistan en buena hora las universidades y colegios mantenidos por el Estado; pero el programa de estudios y el tiempo que dure la enseñanza en una facultad sea enteramente libre y al arbitrio de los maestros. Esto no quiere decir tampoco que el gobierno como representante de la sociedad no vigile al profesorado, impidiendo la introducción de doctrinas perniciosas a la moral y al orden establecido y exigiendo algunas calidades en los maestros, que den garantías a la misma sociedad. Tampoco pretendemos que la libertad de enseñanza se extienda al ejercicio de las facultades literarias: esto sería abrir una ancha puerta al charlatanismo. Si somos partidarios del gran principio económico político de la libertad del trabajo, y en consecuencia rehusamos los gremios, los privilegios y toda traba que se le imponga, esto es, en cuanto a las profesiones industriales, en las que el único e imparcial juez es el público, que da en el mercado la preferencia a lo mejor y más barato; pero en las literarias no sucede lo mismo, y en ellas no tiene más título de suficiencia el que las ejerce, sino el que le da la ley ... Deben existir, por lo mismo, cuerpos sinodales para los exámenes profesionales, pero en los que sólo se exija la capacidad y aptitud perfectamente acreditadas del sujeto. Estos cuerpos no deben ser los mismos de la enseñanza; pues esto sólo bastaría para monopolizarla cerrando la puerta de las facultades a los alumnos de las escuelas rivales." 7 Concluye la comisión visitadora que la Universidad debe reformarse, "para que llene las exigencias de un siglo ilustrado y que camina aceleradamente por la vía del progreso" y que toca al Presidente, con el buen juicio que se le reconoce "decretarlas y ponerlas en ejecución, adquiriendo así un título al reconocimiento público, y aplicándose a una obra de tanto 
interés para todas las clases estudiosas de la sociedad y de tan vital importancia para la nación."

Este informe, que descubre la pura cepa liberal de los firmantes, no fué tenido en cuenta por el presidente de la República, don Ignacio Comonfort, ya que el 17 de septiembre de 1857 expide un decreto que pone nuevamente fin a la Universidad. En él se dispone "que el edificio, libros, fondos y además bienes que le pertenecen, se destinan a la formación de la Biblioteca Nacional, que había sido creada por un decreto de 30 de noviembre de 1846 , y a la mejora de la misma." El rector de la Universidad deberia entregar al del Museo Nacional, por inventario pormenorizado, el edificio de la Biblioteca y todo lo que pertenecía a la Universidad. El director del Museo, que será también de la Biblioteca Nacional, formularía el reglamento de ambas instituciones "consultando lo conducente a la conservación, ampliación y mejora de ellos." Dispone además, que "todos los impresores de la capital tendrán la obligación de contribuir para la Biblioteca con dos ejemplares de cualquier clase que se publiquen; el impresor que faltare a esta prevención se le impondrá gubernativamente una multa de veinticinco a cincuenta pesos, que ingresará a los fondos de la misma biblioteca. ${ }^{8}$

E1 rector de la Universidad, don José María Díez de Sollano, sé enteró del decreto de clausura por su publicación en El Monitor, el 19 del mismo mes de septiembre. $\mathrm{Ni}$ tardo ni perezoso, se aprestó a defender a la Universidad del gravísimo peligro que la amenazaba. Convocó a claustro pleno, al que asistieron veinticuatro doctores. En él se nombró una comisión que quedó integrada por don José Rernardo Couto, don Agustín Carpena y don Urbano Fonseca para que entrevistaran al presidente de la República. Redactó don José Díez de Sollano una exposición para exponer la situación del plantel que regía al presidente de la República y al arzobispo de México y propuso un plan de reformas a la organización de la Universidad.

En síntesis el doctor Díez de Sollano decía: Que no había razón para extinguir la Universidad para establecer una biblioteca cuando, cabalmente, aquélla tiene emprendida y muy adelantada la reposición de su biblioteca pública. En ella se ha reparado toda su estantería, que almacena cinco mil quinientos volúmenes, que serán acrecentados con los que se han pedido a Europa o se han adquirido en Méxi- 
co, en un número que sobrepasa a los mil ejemplares de las obras más importantes en todos los ramos.

Alega el rector, que la Universidad es el cuerpo científico más antiguo de cuantos existen en la República, puesto que ha desempeñado su cometido por más de trescientos años con "historia y gloria," Cuenta además con la sanción del Romano Pontífice. Su historia está "hermanada con las más célebres y esclarecidas Universidades de Europa. Su nombre ha sido siempre respetado por los sabios de todos los países: en la serie del largo catálogo de eminentes hijos que enumera, se marcan no pocos cuyos nombres forman el orgullo nacional por la parte cientifica, figuran alli mismo los hombres más distinguidos de todas en toda carrera literaria, de suerte que sin temor de ser desmentido puede asegurar que esta Universidad cuenta con los más gloriosos antecedentes, que la historia está completamente enlazada, mejor dirá, forma la historia de la ilustración del país y que México puede sin rubor presentar a la faz del mundo la prueba de una sólida y brillante ilustración en la historia de la Universidad." " Agrega además, el rector, sepultaria en el olvido las glorias nacionales de primer orden que son las literarias y pide al presidente extienda su mano protectora hacia esta corporación, ya que ella confirmará prestando, sus eminentes servicios a las Letras, al Estado y a la Iglesia.

En escrito de 23 de septiembre de 1857, el señor Díez de Sollano protesta por la disposición contenida en el decreto de supresión, ya que: "además de la clausura incluye y abraza la confiscación de todos sus bienes; la renovación y destitución de todos sus empleados y arroja sobre los dignos miembros que la componen una bochornosa maniobra de desdoro e ignominia." 10

El plan que propone el rector "para la restauración de la Universidad" en lineas generales es el siguiente:

Habrá tres cátedras para cada una de las ramas de Sagrada Teología, Jurisprudencia, Medicina y Filosofía; tres para la de Bella Literatura, una de ellas será de filología, otra de análisis de los clásicos, y la tercera de estudios de los autores griegos para lo que será menester fundar una cátedra de estudio de la lengua griega. Las de teología, medicina y jurisprudencia se organizarán de una manera análoga a la que estableció el plan del año de 1834. El estudio de la filosofía se hará a través de una cátedra en la que se rea- 
lice el estudio comparativo entre la filosofía antigua y la moderna; otra de metafísica y de la física comparada con la matemática y la última de la matemática y sus varias aplicaciones. Las lecciones serán públicas, semanarias $y$ de dos horas de exposición.

Después de seis años de estudios se votará en el claustro, secretamente y por cédulas, si el estudiante es acreedor a ser condecorado con la borla de la facultad, o si no la tuviere con la de la facultad más análoga. El maestro que no tuviere la borla podrá conseguirla después de tres años de enseñanza si sus discipulos hubieren aventajado o realizado algún esfuerzo notable. Lo mismo la podrá obtener cualquier persona que hubiere realizado obra de extraordinaria distinción.

Para estimular a profesores y alumnos en su trabajo académico se les invitará a leer trabajos en sesiones públicas. Estas disertaciones se publicarán en las memorias de la Universidad. Se recomendará a los maestros que redacten sus lecciones, como medio de elaborar obras adecuadas a la enseñanza en todos los ramos.

Habrá cinco claustros formados por los doctores de las facultades de teología, derecho canónico, derecho civil, medicina y filosofía. Para formarlos en un principio se incorporarán a ellos los doctores que sean necesarios hasta completar un grupo de diez. Presidirá cada claustro el decano. En ellos se discutirán las obras o disertaciones de los profesores que merezcan ser incorporadas a las Memorias.

Los grados menores se conferirán de acuerdo con el reglamento que al efecto se apruebe. "Serán requisito indispensable para toda carrera literaria, sea esta cual fuere." ${ }^{11}$ Los grados mayores serán el de profesor, el de licenciado y el de doctor. "Sin el primero, nadie podrá ejercer su facultad, sin el segundo, nadie podrá ser catedrático de ella en los colegios, y el tercero se requiere para ser rector de cualquier colegio y para lo demás que hasta hoy se ha requerido. ${ }^{12}$ Para obtener el grado de licenciado, el candidato deberá pasar el examen que hasta entonces se ha llamado de "noche triste", previa la disertación que en los términos académicos de entonces se llamaba "repetición". Las cátedras debían cubrirse por oposición.

Los fondos de que disponía la Universidad, serían administrados en la misma forma. El presupuesto era de diez mil pesos, distribuido de la siguiente manera: 
Pago de las cátedras de teología, jurisprudencia, medici-

na, filosofía y literatura a $\$ 500.00$ anuales cada una $\$ 9,000.00$

Para la de griego a $\$ 400.00$, la de mexicano $y$ otomi

a $\$ 300.00$. . . . . . . . . . . . $1,000.00$

$\$ 10,000.00$

La biblioteca continuaría dando servicio eficaz al público y se prestaría atención especial al enriquecimiento de sus acervos.

A las activas gestiones de don José María Díez de Sollano y de la comisión nombrada por el claustro de la Universidad, el gobierno del presidente Comonfort respondió con un seco "no ha lugar" a la derogación del decreto de clausura, en oficio de 26 de septiembre, misma fecha del proyecto del plan. El rector sigue haciendo gestiones desesperadas para mantener viva la Universidad. Consulta al arbozispo de México sobre el destino que se dará a los paramentos, vasos sagrados y demás pertenencias de la capilla universitaria. Redacta, para el gobierno una brillante defensa a los catedráticos y funcionarios de la Universidad. Dice que este plantel tiene fondos que derivan de donaciones y de legados de particulares; "que los doctores han hecho algunas donaciones condicionales, esto es, única y exclusivamente al establecimiento, por lo que, destruido éste, parece muy racional que proporcionalmente sean indemnizados, no sólo por este motivo, sino también por el de propinas que a sus fondos han introducido $\mathrm{y}$ por supuesto que no pueden percibirlas en lo sucesivo, a lo menos deben considerarse acreedores a las cantidades de que con tal carácter se desprendieron, así como de las señaladas para sus honras en su fallecimiento." 13

A pesar de todo prevaleció el criterio político y la Universidad fué legalmente suprimida en el año de 1857 por la administración liberal del presidente Comonfort.

Cambia la situación política en el país, cae el régimen liberal para ser substituído por el conservador que preside el presidente Félix Zuloaga. Triunfan con él las ideas del rector José María Díez de Sollano, que logra la derogación del decreto del 14 de septiembre de 1857, por otro decreto de 5 de marzo de 1858. En el se ordena que "el rector que entonces funcionaba recibirá cuanto pueda pertenecer a la Universidad, en los mismos términos en que se verificó 
la entrega y procederá a reorganizarla con arreglo a sus constituciones y a lo que en este decreto se dispone" que es, en resumen lo que Díez Sollano propuso en 26 de septiembre anterior: "Los doctores de la Universidad procurarán el adelanto y perfección de los conocimientos humanos en la ciencia a que cada uno de ellos se haya dedicado". Esto se realizará por medio de las cátedras que impartan y además, por la lectura de trabajos en sesiones públicas, de redacción de obras de texto y de consulta. Habrá un certamen literario anual a que convocará el rector. Los doctores escribirán las biografías y harán el elogio de sus compañeros fallecidos en el término de cada años.

El claustro pleno mantendrá relaciones con las sociedades científicas, las corporaciones e instituciones literarias del interior y de fuera de la República. Por medio de un inspector se enterará, trimestralmente del estado en que se encuentran los colegios y establecimientos públicos y particulares de estudios preparatorios. Ordenará la formación de un registro general de estudiantes. Vigilará la redacción de la memoria y publicación de los anales. Propondrá, el claustro las reformas necesarias a los estatutos y reglamentos.

El Claustro estará dividido en cinco secciones:

$1^{\text {a }}$ de teología;

$2^{\mathrm{a}}$ de derecho "anónico;

$3^{\text {a }}$ de derecho civil;

$4^{\mathrm{a}}$ de medicina;

5: de filosofía, humanidades o literatura.

Cada sección estaría presidida por su decano y tendrian los componentes del claustro dos reuniones mensuales. Las funciones de cada sección serían: estudiar y aprobar los métodos de enseñanza en su respectiva jurisdicción y determinar los libros de texto que deberían usarse en las cátedras. Visitar por medio de inspectores las clases para cuidar de que en ellas se cumplieran los métodos prescritos y hubiera el orden debido y la exactitud en sus titulares; formular las ternas para los catedráticos substitutos. Las cátedras se cubrirán por oposición. El decreto establece las siguientes cátedras, dotadas con quinientos pesos anuales cada una: de Sagrada Escritu- 
ra; de historia y disciplina eclesiástica y particular de México; de estudio de los Santos Padres de la Iglesia y apología de la religión, de derecho canónico y público eclesiástico; de estudios fundamentales sobre el derecho romano comparado con el patrio; de estudio de los códigos; de medicina legal y moral médica; de historia filosófica de las ciencias médicas; del estudio comparativo entre la filosofía antigua y moderna; de historia general y particular de México; de literatura antigua y moderna. Cuatrocientos pesos se pagarian a los profesores de lengua griega y estudio de los clásicos griegos y latinos y de idioma mexicano y otomí.

Se determinaba que las cátedras eran de perfección y que deberian asistir a ellas los que aspiraran al grado de licenciado o de doctor y los que tuvieran el propósito de consagrarse a la enseñanza "los cuales serán preferidos, en igualdad de circunstancias a los que sin este requisito solicitan alguna cátedra en la Universidad." Las cátedrás se otorgarian por oposición: "cada candidato propondrá el plan de su enseñanza con los fundamentos en que lo apoye." Las lecciones serían públicas de dos horas a la semana. A ellas podrían concurrir aun los que no estuvieren inscritos además de los cursantes en las varias. "Los que por seis años hubieren servido estas cátedras y desempeñado bien sus deberes, con calificación del claustro pleno e informe de la respectiva facultad, obteridrán como premio el grado de doctor en ella y si ya lo tuvieren el de la más análoga." 14

Se les considera en este plan grande importancia a las disertaciones y conferencias que profesores de cada facultad deberían dar por turno semanariamente, con asistencia del rector y de comisiones del claustro a que perteneciera el sustentante. Los grados menores, el bachillerato, serán requisito indispensable para toda carrera literaria y sin ellos. no se podrá matricular ningún estudiante a las facultades. Los mayores son como en el proyecto inicial de Díez de 'Sollano el de profesor, el de licenciado y el de doctor. "Sin el primero nadie podrá ejercer su facultad, sin el segundo nadie podrá ser catedrático de ella en la Universidad y el tercero se requiere para ser rector." El Colegio de Abogados y el Consejo Superior de Salubridad se consideran como corporaciones agregadas a la Universidad, y tendrían en ella lugar para sus reuniones y actos. La biblioteca será pública y se afenderá a los lectores en un turno matu- 
tino y otro vespertino. Los fondos de la Universidad continuarían a su cargo como estaban antes de su extinción y quedarían destinados a los objetos siguientes: $1^{\circ}$ al pago de catedráticos y empleados en los términos del presupuesto; $2^{\circ}$ a los gastos de conservación y reparación del edificio; $3^{\circ}$ a las funciones religiosas, sufragios de los doctores que fallecieren; $4^{\circ}$ a los gastos de secretaría, cobranzas, asistencias y otros menores; $5^{\circ}$ al pago de bibliotecarios y dependientes, compra de libros y suscripción a publicaciones periódicas, científicas extranjeras; $6^{\circ}$ al importe de la impresión de los anales r. la Universidad. Por último el gobierno se reservaba el derecho de recompensar, de una manera particular los grandes e importantes servicios que pudieran prestar los miembros de la Universidad a la educación e instrucción pública.

Con este plan la Universidad volvió del estado en que se encontraba antes de la promulgación del Plan de Tacubaya. Pero los tiempos eran aciagos, poco le duró al benemérito rector Díez de Sollano la alegría de haber dado forma a su proyecto de organización de la Universidad. Invadido México por las tropas de Napoleón, establecido el imperio de Maximiliano en una parte del país, el propio jefe del gobierno se encarga de dar fin, de derecho, a la Universidad. En carta dirigida a su Ministro de Instrucción Pública y Cultos, don Manuel Siliceo, Maximiliano le dice: "Es mi voluntad que la instrucción pública, aprovechando la experiencia adquirida por los pueblos más adelantados, sea puesta en el Imperio mexicano bajo un pie que nos coloque al lado de las primeras naciones. - Como principal guía de sus propuestas, deberá usted tener presente que la instrucción deberá ser accesible a todos, pública $\mathrm{y}$, a lo menos en cuanto se refiere a la instrucción primaria, gratuita y obligatoria. La instrucción secundaria deberá ser organizada de manera que ofrezca por un lado a la clase media de los ciudadanos la educación general correspondiente; por el otro, que sirva de base riecesaria para los estudios superiores y especiales, debiéndose considerar para esto como uno de los más esenciales el estudio de las lenguas clásicas y vivas y el de las ciencias naturales. Las primeras, que son la base de la educación humanitaria, constituyendo al mismo tiempo un inapreciable ejercicio intelectual, siendo además en el día el estudio de las lenguas cultas vivas, absolutamente indispensable para un pueblo que quiere tomar parte en los acontecimientos 
del mundo, y mantener relaciones activas con otros pueblos particularmente refiriéndose a la situación geográfica excepcional del país. En fin, el cultivo de las ciencias naturales es la señal de una época dirigida hacia la realidad, porque nos enseña a ver las cosas que nos rodean, como son en si y a emplear todas las fuerzas del universo en servicio de la voluntad humana. Además quiero que se ponga la debida atención en la educación física y en su armónico desarrollo. - En cuanto a los estudios superiores y profesionales, pienso que para cultivarlos ventajosamente, son precisas escuelas especiales: lo que en la Edad Media se llamó Universidad, ha llegado a ser hoy una palabra sin sentido. Al establecer esas escuelas especiales, deberá usted cuidar que en la diversidad de estudios profesionales sean representados todos los ramos de las ciencias teóricas y prácticas y de las artes. - Quiero que la atención de usted sea dirigida hacia el cultivo de una ciencia muy poco conocida en nuestra patria, es decir, la filosofía, porque ésta ejercita la inteligencia, enseña al hombre a conocerse a sí, y a reconocer el orden moral de la sociedad como una consecuencia emanada del estudio de sí mismo. - En lo referente a la instrucción religiosa quiero también indicarle mis ideas. La religión es cosa de la conciencia de cada uno, y cuando menos se mezcla el Estado en cuestiones religiosas, tanto más fiel queda a su misión. Hemos libertado a la Iglesia, a las conciencias, y quiero asegurarle a la primera el pleno goce de sus legitimos derechos, $y$ al mismo tiempo la entera libertad en la educación y formación de sus sacerdotes, según sus propias reglas, sin ninguna intervención del Estado; pero a ella le corresponden también necesariamente, deberes a los cuales pertenece la enseñanza religiosa, en cuya enseñanza el clero del país, desgraciadamente no ha tomado así ninguna parte hasta ahora. En consecuencia, se inspirará usted en sus proyectos y propuestas del principio que la instrucción religiosa en las escuelas primarias, secundarias, debe darse por el respectivo párroco, según libros aceptados por el gobierno. Los exámenes en todos los establecimientos de instrucción deberán ser arreglados según un nuevo plan, practicados con severa exactitud, y siempre absolutamente públicos; pero si por un lado quercmos en el porvenir exigir de nuestra juventud estudiosa una instrucción sólida y verdadera, por el otro nos impone también esta exigencia la obligación de proporcionar distinguidos profesores para el estableci- 
miento de escuelas normales, a las cuales llamará usted las mayores inteligencias del país y del extranjero; y como segunda necesidad, señalo a usted la de facilitar buenos libros de instrucción que encomiendo particularmente a su cuidado." La carta está fechada el día 11 de junio de 1865. El jefe de un gobierno conservador, se pasaba asi a las filas de un gobierno liberal, al que combatía a sangre y fuego. No sólo sino que, en decreto de 30 de noviembre de 1865 , hacía tabla rasa de lo que su propio partido había hecho en 1858 I daba validez a lo hecho por Comonfort en 1857 . El decreto de Maximiliano dice: "Art. $1^{\circ}$ Se derogan todos los acuerdos y resoluciones dictadas por Nos o por la Regencia del Imperio, que de cualquier manera se opongan a lo prevenido en el artículo $1^{\circ}$ de la ley de 14 de septiembre de 1857, que suprimió la Universidad de México y que se declara vigente. - Artículo $2^{\circ} \mathrm{El}$ actual rector de esta corporación entregará dentro de ocho dias por inventario todos los efectos contenidos en el edificio y que hayan estado a su cuidado, a la persona nombrada por Nos para recibirlos."

Así terminó la tragedia de la Universidad en el siglo XIx. De la historia suscintamente relatada en páginas anteriores, se desprenden las siguientes conclusiones:

10 La acción en pro o en contra de la Universidad fué esencialmente política. El partido conservador hizo cuestión de principio su defensa, el liberal su aniquilamiento.

$2^{\circ}$ Los decretos que extinguen la Universidad realmente borran el nombre, pero dejan vivas muchas de las instituciones que la integraban: las escuelas de medicina, derecho, ingeniería.

$3^{\circ}$ Con el nombre de la Universidad quiere acabar el partido progresista con la enseñanza de la teología y de la filosofía escolástica que en realidad habían venido muy a menos en la Universidad desde el siglo xvir, por el auge que habían alcanzado los seminarios fundados por canon expreso del Concilio de Trento y que habian arrebatado a las Universidades la preparación de los sacerdotes seculares.

$4^{\circ}$ Eliminada la enseñanza de las Artes, de acuerdo con el tipo humanista, la segunda enseñanza quedó sin contenido. El problema de la enseñanza en el siglo xix radicó precisamente, en cómo dar 
forma al nuevo tipo de escuela que capacitara al estudiante para seguir cursos superiores.

$5^{\circ}$ Desde la reforma del doctor Mora se confió a los Colegios Mayores la misión de resolver este problema, que quedó al fin solucionado originalmente, con la fundación de la Escuela Nacional Preparatoria, al triunfo de la República.

$6^{\circ}$ Hubiera sido deseable para la educación superior en México, que el problema de la Universidad no se hubiera planteado y resuelto en el siglo xIx en términos políticos sino académicos y que, como el propio don Justo Sierra lo afirma, se hubiera reformado la institución y no extinguido como sus enemigos pretendieron, aunque esta supresión haya quedado reducida al nombre, a las materias de contenido religioso y a una serie de actos, ceremonias, inherentes a toda universidad, lo que ha dado por restrltado que al reinstalarse, la nueva Universidad ha carecido de una tradición ininterrumpida que da fuerza a toda institución respetable. Muchos de los tropiezos que ha sufrido la Nueva Universidad se han debiclo a la falta de esta continuidad histórica.

$7^{\circ}$ Al romperse el nexo entre todas las escuelas que constituian 1.a Universidad en el año de 1865 , se creó un estado de anarquía que influyó apreciablemente en la educación superior de nuestro país.

$8^{\circ}$ Al reinstalarse la Universidad Nacional en 1910, el pie veterano de ella fueron los planteles que habian sobrevivido a los acontecimientos del siglo xix y renació la filosofía en los planes de estudio de la flamante institución.

\section{RESURRECCION DE LA UNIVERSIDAD}

Al triunfar la República en el año de 1867, el estado de la educación superior era el siguiente: la Universidad suprimida de nombre, clıminados los estudios teológicos, metafísicos y filosóficos; pero existentes las escuelas en que se cursaban las profesiones liberales: juriprudencia, medicina, ingeniería. La educación secundaria se encontraba, prácticamente desorganizada, corría a cargo de lo que quedaba de los Colegios Mayores, particularmente del de San Grego- 
rio. Todos estos planteles dependían del Ministerio de Justicia. Subsistía la Escuela de Comercio, fundada hacía poco y dependiente también de ese Ministerio, y la de Agricultura y Veterinaria, que pertenecía al cuadro de actividades de la Secretaría de Fomento.

Para organizar la educación pública en todos sus aspectos se expidió la Ley de 2 de diciembre de 1867. En ella se afirmaba la fe en la instrucción. La ilustración en el pueblo "es el medio más seguro y eficaz de moralizarlo y de establecer de una manera sólida la libertad y el respeto a la Constitución y a las leyes. Determinaba una orientación filosófica en la enseñanza: el positivismo. Había que sustituir una doctrina, la católica, por la positivista, aunque en la organización del sistema "se sacrificó por eso la triste religión de la humanidad tan caramente postulada por Comte. Pugnaba en su contra el principio político liberal llamado de libertad de conciencia. Pero los positivistas mexicanos siempre echaron de más el vacio y, por eso, hombres como Sierra hablaban a cada rato de la religión de la ciencia, y se referían a su capilla como si se tratara de una iglesia, Babel, a donde Dios, es decir la Verdad ha bajado para reunir al disperso género humano con los vínculos de un lenguaje, sólo el lenguaje universal de la ciencia" - como acertadamente expresa O'Gorman- citando a Sierra. ${ }^{15}$

El fundamento del plan de la enseñanza secundaria o preparatoria se encontró en el estudio basado en la serie lógica de las ciencias; en la abstención a las inaccesibles e inútiles investigaciones de cattsas eficientes y esencias; fe en las leyes de invariable sucesión, de constante coexistencia y de relativa similitud de los fenómenos. E1 propósito de los autores del plan era habituar la conducta de los educandos a la previsión científica, fundamento de la actividad racional. Así nace la Escuela Nacional Preparatoria. Su lema será el positivista "Libertad, Orden y Progreso", que se cambia después en "Amor, Orden y Progreso". La base del estudio serán las ciencias, sin embargo, se da un sitio no muy prominente a la metafísica, las lenguas clásicas y la ideología. En Jurisprudencia subsiste el derecho eclesiástico.

La Ley Reglamentaria de 24 de enero de 1868, modifica un tanto el plan original. Hace obligatoria, por ejemplo, la metafísica para los que deseen continuar estudios de derecho. Establece, en cambio los estudios de Historia General y de México como obligatorios 
para todos los estudiantes. Se concebía a la Preparatoria como un tránsito para todas las profesiones y vaciaban los estudios de una a otra carrera.

Se expide una nueva Ley en 15 de mayo de 1869, que se reglamenta en 9 de noviembre del mismo año. En ella se establece una Preparatoria única y se suprime del plan de estudios la metafísica y el derecho eclesiástico. Se perfecciona en ambos ordenamientos la aplicación del positivismo a la segunda enseñanza.

En 1880 se inicia una ofensiva contra el positivismo como doctrina que da vida a la enseñanza. Nace de la discusión apasionada de un texto de Lógica, el de Bain, que pretende ser sustituído por el krausista de Tiberghien. El ministro Mariscal apoya el segundo contra el primero. "Ya una junta de profesores de la Preparatoria había atacado al texto de Bain imputándole tres cargos capitales. Primero, abogaba, decían, por un sistema corruptor que niega la posibilidad de una vida de ultratumba; segundo, era anticonstitucional, porque implicaba un ataque a la libertad de conciencia y, tercero, la opinión pública lo había condenado. El ministro Mariscal, es decir, el gobierno, hizo suyas estas críticas, y pasando a más, creyó no extralimitarse, al señalar el texto que substituiría al repudiado". ${ }^{16}$

Por esta época hace su aparición don Justo Sicrra, defensor entonces del positivismo, combatido incluso, por funcionarios oficiales. La puntería va dirigida a suprimir la Escuela Nacional Preparatoria. Sierra pide, entonces, la resurrección de la Universidad. En la Cámara de Diputados una comisión que presidia don Manuel Payno consultaba la supresión de la Preparatoria, de la Escuela de Agricultura y la de Bellas Artes: "Si para algo sirve la observación y la experiencia, ésta nos enseña que tales establecimientos, mientras no se sistemen de una manera conveniente, no podrán desempeñar el objeto para que fueron creados. Si el sistema que domina en el plan de estudios y sus reformas es el escolar, de nada sirve la Preparatoria. Es una especie de garita donde se detiene el alumno cinco años, al cabo de los cuales piensa en dedicarse a una carrera especial o no dedicarse a ninguna." Habla la Comisión de un plan que el gobierno presentaría en breve para dar una mayor consistencia a la educación pública. En efecto, el ministro don Ezequiel Montes publicaba en abril de 1881 un proyecto de Ley orgánica de instrucción pública. Don Justo Sierra lo ataca y propone el resurgimiento 
de la Universidad. Veamos lo que dice O'Gorman sobre este proyecto de ley del maestro Sierra: "17 "Si Sierra queria Universidad, la querría positivista; si en ella quería salvar a esa doctrina, querría a la nueva institución independiente desde el punto de vista académico; si, en fin, quería que el positivismo continuara gozando dè favor oficial, querría que la Universidad formara parte del gobierno. Pues bien, el proyecto de Sierra responde con precisión a estas tres vitales exigencias. $\mathrm{El}$ artículo $7^{\circ}$ consagra la adopción del positıvismo como doctrina básica de la instrucción universitaria; el artículo $2^{\circ}$ declara la emancipación científica de la proyectada. Universidad, y el artículo $6^{\circ}$ enuncia cuáles habían de ser los lazos que la estructuraran dentro de la administración pública."

Ia Universidad había adquirido sentido nuevo en la segunda mitad del siglo $\mathrm{xIx}$. Las vicisitudes que habían padecido planteles de este género, la Sorbona in capite se habian allanado. Las universidades alemanas eran centros de gran importancia científica. La enseñanza universitaria, adquiría, en el vecino país del norte, los Estados Unidos, un gran desenvolvimiento. ¿Era posible que México no tuviera una institución de esta naturaleza? ¿Podia la enseñanza superior continuar desarticulada y a merced de los caprichos del poder público? Don Justo Sierra, que pedía el restablecimiento de la Universidad como diputado al Congreso federal, había de realizar su sueño como Secretario de Instrucción Pública y Bellas Artes, treinta años después.

La Universidad Nacional fué reinstalada solemnemente el día 22 de septiembre de 1910, en acatamiento de su Ley constitutiva expedida el 26 de mayo de ese mismo año. Quedó integrada por las Escuelas Nacionales Preparatoria, de Jurisprudencia, de Ingenieros, de Bellas Artes (en lo concerniente a la enseñanza de la Arquitectura) y de Altos Estudios. Quedarían bajo su dependencia otros institutos superiores: los que fundaran con sus recursos propios previa aprobación del Presidente de la República y los que incorporare en lo futuro. El gobierno de la Universidad estaría constituido por el rector y el Consejo Universitario.

La inauguración fué uno de los actos más solemnes de las fiestas conmemorativas del primer centenario de la Independencia. Concurrieron a ella representantes de las universidades extranjeras. $\mathrm{Y}$ el nuevo centra de estudios nació bajo el patrocinio de las hermanas 
de Salamanca, Paris y California. El discurso inaugural pronunciado por el Secretario de Instrucción Pública y Bellas Artes don Justo Sierra, ha sido una de las oraciones académicas más notables que se hayan pronunciado en México. Don Edmundo O'Gorman en su artículo "Justo Sierra y los orígenes de la Universidad en 1910" le ha dado toda la importancia que ese discurso tiene en la historia de las ideas de nuestro país y ha valorado lo que significa en el pensamiento de su autor.

Los viejos y tradicionales enemigos de la Universidad no se daban, sin embargo, por vencidos. A la añeja pugna de liberales y conservadores, que había significado para la Universidad la alternativa de muerte y resurrección en el siglo xIx, se sumaban ahora otros elementos que no veían con buenos ojos la reinstalación de un plantel que tenía una tradición varias veces secular. Don Justo Sierra había cuidado bien de expresar en su discurso que la Real y Pontificia Universidad no era el pasado de la recién nacida y habia hecho la crítica de los métodos de enseñanza que se seguía en la Universidad virreinal. Crítica apasionada y que respondía a la manera de entender la Edad Media mexicana de los discípulos, aunque estuvieran ya un tanto emancipados, del positivismo. No todo el mundo podía comprender esta sutil diferencia, entre lo pasado y lo antepasado. La enemiga contra todo lo que recordara la dominación española quedaba en pie y a ella venían a sumarse otras pasiones que ya actuaban en la vida pública del país. Los positivistas veían en la nueva institución una amenaza contra el sistema que, con más o menos integridad en su ideario, había dominado en la enseñanza pública de México y no perdonaba que se abrieran las puertas del templo a la implorante por tantos años expulsada de su recinto. Otro grupo argüía que en un país de analfabetas no se explicaba la existencia de una Escuela de Altos Estudios, en donde se iba a enseñar la ciencia pura por eminencias extranjeras como el antropólogo Franz Boaz o el botánico Reiche. Las dos piedras de toque seguirian siendo, dentro de la Universidad, la Escuela Nacional Preparatoria y la de Altos Estudios. Las demás como tenían un fin concreto, el de formar profesionistas, y habian subsistido a pesar de no existir la Universidad, no eran objetadas. 
Dos meses después de reinstalada la Universidad se iniciaba en Pucbla el movimiento revolucionario contra el gobierno que la había creado, y triunfaba en el mes de mayo de 1911. A los enemigos de la flamante institución se sumaban ahora los del régimen desaparecido. No es extraño, pues, que al discutirse el presupuesto de egresos para el ejercicio de 1913, en los últimos meses del año precedente se haya desatado en el Congreso una violenta oposición contra las partidas que garantizaban el sostenimiento de la Universidad $y$, en especial, las referentes a la Escuela de Altos Estudios y se propusiera su supresión. Don Ezequiel $\mathrm{A}$. Chávez, colaborador de don Justo Sierra en el proyecto de reorganización de la Universidad y diputado por entonces, hizo la defensa de la institución $y$, ayudado por otros representantes, logró se salvaran las partidas correspondientes.

El año de 1914 se inició con una reforma fundamental en el Plan de Estudios de la Escuela Preparatoria, alma de ella fué don Pedro Henríquez Ureña y la autoridad encargada de implantarla, don Nemesio García Naranjo, Secretario de Instrucción Pública en el gobierno de Huerta. Al viejo plan barrediano, sostenido hasta entonces en sus principios fundamentales, se le incorporaron una serie de cátedras traídas del campo de las humanidades. La anunciada incorporación de la Filosofía a la Universidad, no fué sólo en el curriculum de la Escuela de Altos Estudios. Se creaban ahora unas conferencias en la Escuela Preparatoria en las que don Antonio Caso expondría los problemas filosóficos vistos a la luz de la filosofía de la intuición, que el maestro explicaba por entonces, con entusiasmo. Se darian, además, a los estudiantes preparatorios conferencias sobre Historia del Arte. Las clases de Historia de México e Historia General merecían la atención del autor del nuevo plan, dando a estas enseñanzas la importancia que no habían tenido en épocas precedentes. Se fundaba una cátedra de literatura mexicana e iberoamericana. Un grupo nuevo de catedráticos, discípulos de Pedro Hentíquez Ureña, traían un aliento de juventud y de esperanza a la Escuela Preparatoria. El maestro confesaba que el nuevo Plan no era simplemente una adición de nuevas enseñanzas al antiguo de la Preparatoria, sino que se proponía en realidad un cambio en las 
tendencias de la enseñanza Preparatoria, una inyección de humanismo, a la instrucción marcadamente científica de la época anterior. El nuevo Plan fué flor de un día.

$$
\begin{aligned}
& \text { JuLio Jiménez Rueda, } \\
& \text { Universidad de México. }
\end{aligned}
$$

$$
\mathrm{NOTAS}
$$

1 O'Gorman, "Justo Sierra y los origenes de la Universidad en 1910", en Filosofía y Letras, revista de la Facultad de Filosofía y Letras, No. 33, eneromarzo de 1949, p. 35.

2 Historia de América española, tomo III, México. Editorial S. Calleja Madrid, 1924, p. 370.

3 O'Gorman, op. cit., p. 44.

4 O’Gorman, op. cit., p. 45.

5 Documento xir. Ministerio de Justicia. Negocios Eclesiásticos e Instrucción Pública en Apéndice a la Crónica de la Real y Pontificia Universidad, de Cristóbal Bernatdo de la Plaza. México, 1931, pp. 433-445.

6 Apéndice cit., pp. 441-442.

7 Apéndice cit., p. 445.

8 Documento xIv en apéndice de la obra citada, p. 446.

9 Documento No. 2 en el apéndice ya citado, p. 449.

10 Documento No. 4, en el apéndice ya citado, p. 450.

11 Plan, en el apéndice referido, p. 455.

12 Op. cit., p. 455.

13 Op. cit., p. 459.

14 Apéndice citado, p. 664.

15 "Justo Sierra y los orígenes de la Universidad en 1910", en Filosofía y Letras, tomo xvII, número 34, abril-junio de 1949, p. 223.

16 O'Gorman, op. cit., p. 232.

17 O'Gorman, op. cit., p. 235. 
